\title{
KONCEPT MEŠOVITE NAMENE: PROGRAMSKI HIBRID U ITALIJANSKOM GRADU LATINI
}

\section{THE CONCEPT OF MIXED-USE: PROGRAMMATIC HYBRID IN ITALIAN CITY LATINA}

\author{
Sofia Rudan, Jelena Atanacković-Jeličić, Fakultet tehničkih nauka, Novi Sad
}

\section{Oblast - ARHITEKTURA I URBANIZAM}

Kratak sadržaj - Inspirisani neprekidnim promenama savremenog društva, problematika ovog istraživanja smeštena je u kontekst današnjeg grada kao nečovekomerne sredine podređene automobilu. Ispituju se teme programskog kombinovanja, društvene uloge grada, arhitekture koja može da odgovori na potrebe društva 21. veka. Akcenat je na prekidu sa principima tipološkog projektovanja i uvođenju modela kombinovanih namena $i$ hibridne arhitekture $u$ cilju generisanja socijalnog kontakta. Kao rezultat istraživanja predložen je projekat arhitektonskog hibrida u italijanskom gradu Latini.

Ključne reči: Mešovita namena, program, funkcionalna kombinacija, hibridna arhitektura

Abstract - Inspired by our society's continuous flows of changes, the research issue takes place in the context of nowadays cities represented as spaces designed without human dimension and highly monopolized by automobile usage. The topics of programmatic combination, social implication of the urban environment, architecture that is capable of responding to the needs of the society of the $21^{\text {st }}$ century have been examined. The research emphasizes the relevance of neglecting the principles of typological design and introduces the concepts of mixed-use and hybrid architecture, models that are able to generate social interaction. As a result of the theoretical research, the project of architectural hybrid placed in the Italian city Latina has been proposed.

Keywords: Mixed-use, program, functional combination, hybrid architecture

\section{UVOD}

Fizička struktura grada nastaje kao prostorno-fizički izraz složenih i dinamičnih prirodnih, ekonomskih, socijalnih i tehničko-tehnoloških sila [1]. Društvena uloga grada, nekada najrelevantnija komponenta koja snažno definiše urbanu sredinu, u kontekstu savremenog društva 21. veka obeleženog globalizacijskim i tehničko-tehnološkim procesima, izgubila je svoj značaj. Nagla urbanizacija, podstaknuta industrijalizacijom, donosi korenite promene $u$ fizičkoj organizaciji urbane sredine koje su se reflektovale u težnji za prekomponovanje gradskih sadržaja. Modernistički koncept separacije funkcija grada koji negira javni prostor kao generator socijalne interakcije uslovio je

\section{NAPOMENA:}

Ovaj rad proistekao je iz master rada čiji mentor je bila dr Jelena Atanacković-Jeličić, red. prof. masovnu upotrebu motornih vozila na dnevnom nivou $\mathrm{i}$ snažno uticao na potpuni gubitak socijalne i kulturne funkcije grada.

Tema istraživanja su sve popularniji koncept kombinovane namene (mixed-use concept) u urbanističkom i arhitektura hibrida (hybrid) u arhitektonskom projektovanju. Ovi koncepti zasnivanju se na integrisanju različitih funkcija $u$ definisanim prostornim okvirima u cilju ostvarivanja raznovrsnosti i vitalnosti kroz obezbeđivanje intenziteta korišćenja, budući da namene direktno utiču na socijalnu aktivnost $\mathrm{i}$ interakciju. Upravo ovi novi modeli nastali kao raskid sa tradicionalnim projektovanjem po tipološkim principima, a u praksi još nedovoljno eksploatisani predstavljaju predmet ovog rada.

Kao rezultat istraživanja, u okviru master rada predstavljen je projekat „Garage Museum“. Koncept projekta, kao direktna primena filozofije mešanja namena, zasniva se na, ne samo nesvakidašnjem programskom kombinovanju $\mathrm{u}$ okviru jednog objekta, već i na programskoj promenljivosti i prostornoj adaptibilnosti. Cilj projekta je da svojim sadržajima proisteklim direktno iz konteksta, generiše socijalnu interakciju i doprinosi jačanju kolektivnog identiteta. Pored toga, jedna od tema projekta jeste, u cilju redukovanja dominantne uloge automobila u savremenom životu, redefinisanje programa parking garaže kao nehumanog monofunkcionalnog prostora podređenog automobilu u multifunkcionalan prostor sa društvenom implikacijom.

\section{PROGRAM U ARHITEKTURI}

Program je definisan kao sistem namera kojima se definišu prostorni odnosi kuće. Pokušaj sistematizacije odnosa prostora i programa rezultirao je utvrđivanjem tipologija, koje od kasnog 18. veka postaju osnovni model rada u arhitekturi. Kritike koje je donela post-moderna ogledaju se u oživljavanju interesovanja za testiranje programa i odbacivanju tradicije tipološkog pristupa.

\subsection{Umetnost kombinovanja programa}

Fragmentacija savremenog života neizbežno navodi na nova i dosad neviđena pregrupisanja njegovih delova. Nepovezani u koherentnu celinu, nezavisni o svojoj prošlosti, ti autonomni fragmenti mogu se iznova kombinovati kroz serije permutacija čija pravila nemaju ništa zajedničko s pravilima modernizma. Iz savremenih problema distribucije namena u odnosu na formu proistekla je pojava objekata kombinovane namene, pre svega u funkciji ,sumiranja svih delova". Takva koncentracija različitih namena i hibridizacija predstavlja dinamičan proces aktivacije strukture, individualnih namena i urbanog tkiva koje okružuje strukturu. 


\section{KONCEPT MEŠOVITE NAMENE}

\subsection{Fenomenološko razmatranje}

U svom osnovnom značenju, mešovita namena predstavlja koncept kombinovanja dve ili više različitih funkcija integrisanih u jedinstveni prostor. Spontano nastao razvojni obrazac - mešanje različitih namena u okviru istog područja - koji se primenjivao tokom čitave istorije urbanizacije, evoluirao je do kompleksnog teorijskog modela koji podrazumeva mnogo više od proste sume raznovrsnih sadržaja. Iako je ovaj koncept poznat dugi niz godina, u sadašnjem trenutku još uvek predstavlja fenomen podložan ispitivanju i nemoguće ga je egzaktno definisati budući da ga oblikuje veliki broj promenljivih.

\subsection{Razlozi implementaciju koncepta mešovite namene} Razlozi za eksploataciju koncepta mešovite namene u realnom fizičkom i vremenskom kontekstu su mnogobrojni, međutim ovi benefiti se ne mogu prihvatiti kao apsolutno rešenje problema današnje urbane sredine. Uspeh ovog koncepta u najvećoj meri zavisi od lokalnog konteksta, ne samo fizičkog već i ekonomskog, socijalnog, kulturnog i slično. Kuplend deli prednosti ovog koncepta na podrazumevane (definite) i potencijalne (possible) [2].

\section{MEŠOVITE NAMENE U RAZLIČITIM ISTORIJSKIM KONTEKSTIMA}

Koncepti kombinovanja programa i mutifunkcionalnosti nisu novi fenomeni, već su eksploatisani u arhitekturi još od antičkog doba. Tokom istorije, ove ideje su bile prisutne kao manje ili više prihvaćene, a uvek suštinski povezane sa ideologijom, tehnologijom i trendovima vremena.

\subsection{Antički grad kao model mixed-use koncepta}

Prve modele mešovite namene predstavljaju gradovidržave u antičkom dobu. Ograničena priroda kretanja i onemogućena teritorijalna ekspanzija zbog gradskih zidina predstavljaju dva relevantna uslova za formiranje tadašnjih gradova. Kao posledica ovih uslova, gradovi su predstavljali gusto izgrađene homogene celine u kojima su organski integrisane različite funkcije koje su se prožimale, kombinovale, smenjivale bez mogućnosti njihove segregacije ili zoniranja.

\subsection{Grad kao sinteza monofunkcionalnih zona}

Kao posledica tehnološkog napretka uvodi se sistem masovnog tranzita koji je omogućio povećanu mobilnost i doveo do dramatične ekspanzije gradskog jezgra. U periodu nakon Industrijske revolucije prvi put se javlja funkcionalna separacija u cilju diferenciranja novoizgrađenih industrijskih kompleksa i objekta stanovanja kao i uspostavljanja „zdravog“ grada. Zahvaljujući konceptu zoniranja propagiranom od strane lokalnih vlasti trgovina, stanovanje, proizvodnja i drugi programi su bili odvojeni jedni od drugih, a ideje o kombinovanoj nameni su bile retke i neprihvaćene.

\subsection{Funkcionalna segregacija ili kombinacija}

Period nakon Drugog svetskog rata predstavlja prekretnicu u istorijskom razvoju koncepta mešovite namene. Prvi put u istoriji urbanog planiranja obrazovale su se struje koje zastupaju različite teorije o ideji funkcionalne organizacije savremenog grada 20. veka - sa jedne strane CIAM na čelu sa Le Korbizjeom koji na evropskom tlu propagiraju principe „Funkcionalnog“ grada, a sa druge američka praksa koja uvodi koncept hibridne arhitekture, „Otvorenog“ grada i kombinovanja funkcija u najvećoj meri zahvaljujući autorki Džejn Džejkobs.

\subsection{Mixed-use kao revolucionarna ideja 21. veka}

Zasnovan na teorijama organskog grada Džejn Džejkobs, osamdesetih i devedestih godina na američkom tlu, obrazuje se pristup u urbanom planiranju „Novi urbanizam” koji u žižu interesovanja vraća tradicionalni pristup planiranja po meri čoveka. Nastao kao snažan otpor suburbanom razvoju i monofunkcionalističkoj podeli grada, ovaj pokret se zalaže za koncept mešovitih namena na nivou susedstva u cilju ostvarivanja osećaja zajednice.

\section{HIBRIDNA ARHITEKTURA}

Hibridnost je postupak ukrštanja heterotropnih elemenata tako da nastane jedna nova kompaktna struktura. Hibridna arhitektura je takva arhitektura koja kombinuje u sebi formu i funkciju dva ili više objekta. Kao odgovor na enormni porast cena zemljišnih parcela $u$ američkim gradovima, krajem 19. veka u Sjedinjenim Američkim Državama javlja se ideja hibrida kao arhitektonske megastrukture koja svojim volumenom postiže maksimum iskorišćenosti zemljišta.

\subsection{Grad kao jedinstveni objekat}

U određenim slučajevima, hibridna arhitektura kondenzuje programe čitavog grada omogućavajući određeni nivo samodovoljnosti u odgovoru na dislociranu lokaciju. Potreba da se obezbedi nivo različitosti dostupne u urbanim zonama čini od ovih struktura mikrokosmos ili pojavu grada-u-gradu. Hibrid ima karakter super-zgrade, superbloka, megastrukture ili zgrade-kao-grada (City-as-a-SingleBuilding). Ideja o gradu pod jednim krovom Rejmonda Huda kulminaciju je doživela nekoliko decenija kasnije u inovativnim projektima avangardnih arhitektonskih timova poput Arhigrama, Superstudia, Arhizuma i japanskih Metabolista, čiji se radovi nazivaju ,proto-hibridima”.

\section{MORFOLOGIJA MIXED-USE OBJEKATA}

Hibridizaciju prati određena forma veličine, sjaja i gigantizma, kako mešanje programa i multifunkcija najčešce impliciraju određenu veličinu. U praksi se najčešće eksploatišu dva morfološka tipa u kojima se integrišu kombinovane namene - disperzni (grupna forma) i koncentrisani (megastruktura). U zavisnosti od anatomije forme objekta mešovite namene, Fenton izdvaja tri kategorije - uklopljeni hibrid (Fabric Hybrid), kompozitni hibrid (Graft Hybrid) i monolitni hibrid (Monolith Hybrid) [3].

\section{MEŠOVITE NAMENE U SAVREMENOM DRUŠTVENO-EKONOMSKOM KONTEKSTU}

\subsection{Grad kao društvena tvorevina}

Urbana sredina se ne može definisati isključivo kao fizička artikulacija prostora u kojoj primat imaju raznovrsne delatnosti, već se njen značaj ogleda u njenoj društvenoj funkciji. Grad predstavlja platformu koja nudi diverzitet, mnogostran život, društvenu interakciju i disharmoniju, konflikt pa čak i dramu koji nedostaju selima i predgrađima. Samim tim, dolazi se do zaključka da grad ne definišu objekti i infrastruktura već da su oni samo deo neizostavne društvene sheme. 


\subsection{Problemi društvene funkcije grada 21. veka}

U kontekstu savremenog društva 21. veka, opčinjenog novcem, gigantizmom i tehnologijom, u trci za ekonomskom moći i praćenjem aktuelnih trendova, a pod velikim uticajem glavnih donosionca odluka, zanemarila se društvena funkcija grada i činjenica da grad definišu njegovi korisnici, a ne zgrade i infrastruktura. Globalizacijski procesi praćeni široko rasprostranjenom komunikacijskom infrastrukturom poput Interneta omogućili su povećanu slobodu kretanja ljudi, dobara, distribuciju i razmenu informacija i ideja ali samim tim redukovali društvenu interakciju u realnim fizičkim okvirima.

\section{3. Čovek/Automobil kao mera grada}

Upravo u kompleksnom kontekstu današnje urbane sredine gubi se fundamentalni princip arhitektonskog i urbanističkog projektovanja da je čovek mera građene sredine, a tehnološka revolucija je poput akceleratora „lansirala” automobil kao centar oko koga se formira čitava građena sredina. Kao produkt masovne proizvodnje i potrošnje te donosioc kapitala, automobil postaje osnov oko kojeg se formira čitav grad i koji diktira sve njegove aspekte. Povećana mobilnost stanovništva generisala je teritorijalnu ekspanziju gradskog jezgra, ubrzala procese suburbanizacije, decentralizacije i uslovila izgradnju infrastrukture.

\section{TIPOLOGIJA JAVNE GARAŽE U KONTEKSTU MIXED-USE KONCEPTA}

$\mathrm{S}$ obzirom da je u sadašnjem trenutku nemoguće korenito eliminisati automobil i potrebu za realizacijom parking garaža, postavlja se pitanje na koji način redefinisati ovu tipologiju tako da da njena upotreba bude intenzivnija i u službi čoveka. Poslednjih nekoliko godina, u arhitektonskoj praksi osećaju se napori da se unapredi dizajn ove tipologije ne samo u formalno-estetskom već i u programskom smislu. Injektiranjem programa koji će generisati društvenu interakciju u strukturu koja je potpuno autoorijentisana, postiže se socijalna implikacija i angažovanost koje su i glavni cilj arhitekture.

\section{PROJEKAT GARAGE MUSEUM}

\subsection{Projektni zadatak}

Inspirisan ovim kompleksnim kontekstom sa kojim se suočava arhitektonska praksa, studio Arhitektonskog projektovanja na Politehničkom fakultetu u Milanu $\mathrm{u}$ letnjem semestru 2019. godine se bavi temama kulturnih prostora, aktivnog građanstva i kolektivnog identiteta. Postavlja se pitanje šta je kultura danas, na koji način se prostornom manipulacijom mogu generisati kulturni sadržaji i kreirati okruženje u kom se razvija socijalni identitet. Kao projektni zadatak na studiju, u okviru zadatog šireg konteksta grada Latine, bilo je neophodno ponuditi arhitektonsko rešenje koje integriše kombinaciju različitih aktivnosti.

\subsection{Lokacija: istorijska i sociološka vrednost konteksta}

Latina je grad situiran na području Pontinske ravnice (Pontine Marshes) u italijanskoj pokrajni Lacio šezdeset kilometara južno od Rima i predstavlja jedan od najmlađih gradova u Italiji nastao kao posledica reklamacije. Početkom dvadesetog veka od strane fašističkog vođe Benita Musolinija pokrenuta je reklamacija Pontinske ravnice, nekadašnje močvarne oblasti zaražene malarijom, koja je podrazumevala isušivanje oblasti i saniranje bolesti uvođenjem kanalizacione infrastrukture i osnivanje tri fašistička grada - Litorije, Imperije i Aprilije.

U okviru šireg obuhvata definisanog projektnim zadatkom, za lokaciju konceptualnog rešenja odabran je trg San Benedeta. Ova parcela trougaone morfologije situirana je $u$ centralnom jezgru grada Latine, nedaleko od Piazze di Popolo. U sadašnjem trenutku, u granicama odabrane lokacije prisutna je sinteza različitih programskih celina koje koegzistiraju na trgu bez međusobne interakcije - javni parking za automobile na površini trga i dva slobodnostojeća objekta, bivša garaža Ruspi i Casa dell'Architettura.

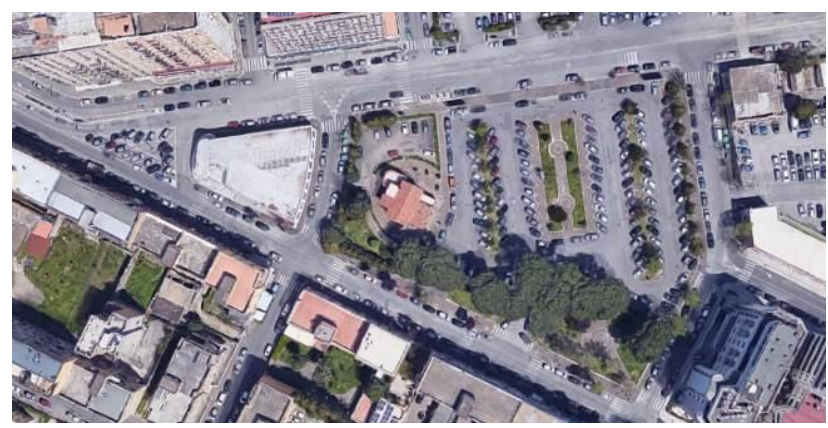

Slika 1. Postojeće stanje trga San Benedeta

\subsection{Projekat javne biblioteke u Latini}

Projekat koji je u različitim aspektima razrade koncepta snažno uticao na projekat Garage Museum jeste konceptualno rešenje britanskog arhitekte Džejmsa Stirlinga za javnu biblioteku na trgu San Benedeta $u$ Latini osamdesetih godina 20 . veka

\subsection{Konceptualizacija rešenja}

Konceptualno rešenje za projekat „Garaža Muzej” zasniva se na detaljnoj analizi konteksta grada Latine i potreba njegovih stanovnika. Glavna ideja projekta jeste da novi objekat svojom prostornom i programskom strukturom predstavlja ekstenziju postojećih objekata. Budući da je dominantna funkcija sadašnjeg trga parking za automobile, glavno pitanje ovog projekta jeste na koji način integrisati program parkinga i kulturne sadržaje tako da oni budu u interakciji i generišu dinamičnost. Kao odgovor na ovo pitanje formira se koncept hibridne strukture, objekta mešovite namene, koji u svojim prostornim okvirima integriše niz potpuno različitih programa koji nisu samo distribuirani unutar objekta bez interakcije, već se prožimaju, nadovezuju, smenjuju i po potrebi transformišu u drugi program. Novoprojektovani objekat nije centar lokalne zajednice, nije garaža, nije muzej, nije biblioteka, nije „Kuća arhitekture ”, nije kulturni centar već je sve od navedenog i mnogo više.

\subsection{Prostorna i programska struktura novoprojektovanog rešenja}

Novoprojektovani objekat mešovite namene pozicioniran je na centralnoj osi trga duž koje se nalaze postojeća dva objekta. Ova središnja osa pored toga što vizuelno povezuje slobodnostojeće objekte u celinu i dovodi ih $u$ zajednički dijalog, ona ujedno predstavlja i glavnu osu pešačke komunikacije između tri objekta. Različiti programi integrisani u novi objekat distribuirani su po vertikalnoj i horizontalnoj osi. Funkcije se prelivaju jedna 
u drugu obrazujući fluidan prostor, bez naglog prekida ili osećaja ulaska u nepoznatu funkcionalnu celinu. $\mathrm{Na}$ mestima presecanja različitih programa organizovani su izrazito fleksibilni prostori za socijalizaciju.

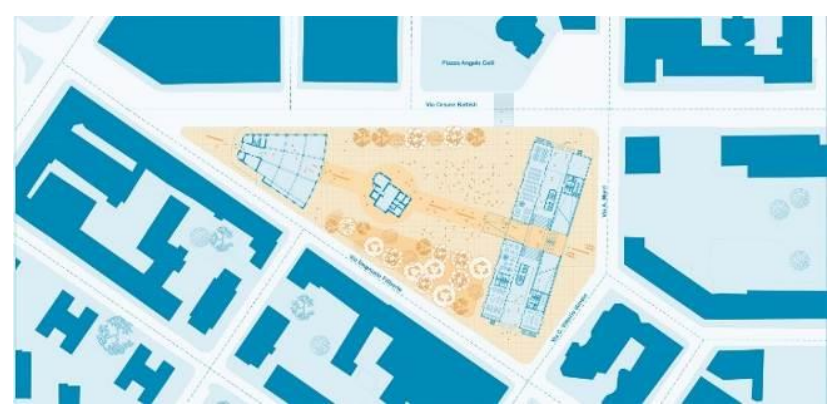

Slika 2. Situacija sa prizemljima objekata

\subsection{Forma i materijalizacija}

Cilj je bio da se ne stvori strog prostorni raspored koji diktira i ograničava mogućnosti upotrebe prostora, već samo prostorni okvir za mnogobrojne intervencije koje će generisati dešavanja i buduće funkcije objekta. $U$ tom smislu, spoljašnja forma objekta je jednostavna i predstavlja opnu koja ograničava kompleksnu strukturu unutrašnjeg prostora. Integrisanjem elemenata rampe, pasarele i galerije sa velikom količinom otvora u pločama formira se fluidan prostor karakteristične atmosfere i dinamična sredina $\mathrm{u}$ kojoj se distribuirani programi prepliću.

\subsection{Konstruktivni sklop}

Za kontruktivni sistem izabran je skeletni sistem sa armirano-betonskim nosećim elementima kao najbolje rešenje za prostornu strukturu objekta. Raspon stubova diktiran je sistemom galerija i rampi kako bi se obezbedilo nesmetano funkcionisanje kolskog saobraćaja i parking prostora, te se raster sastoji neizmenično od polja od 8 i 9.5 metara.

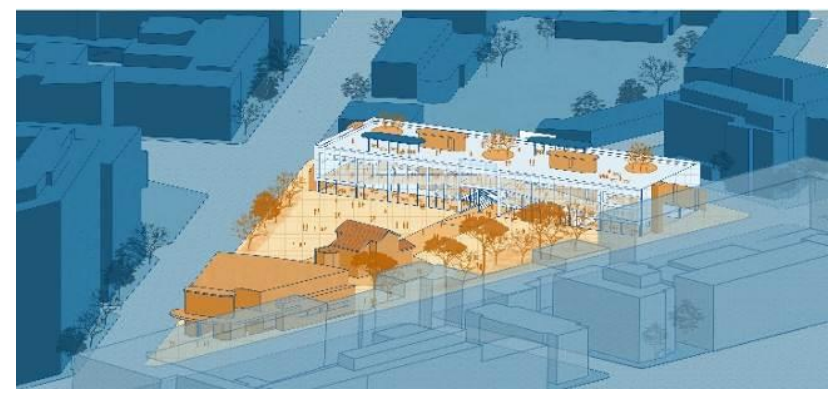

Slika 3. Izometrijski prikaz novoprojektoanog rě̌enja

\section{ZAKLJUČNA RAZMATRANJA}

Veoma je važno suštinsko shvatanje grada kao živog organizma koji stalno evoluira, a čije čelije ne predstavljaju zgrade i putevi, već njegovi stanovnici. Ustaljeni principi projektovanja po tipološkim obrascima nisu u skladu sa turbulentnim kontekstom savremenog društva čije potrebe oblikuju prostor. Proces projektovanja bi trebao da se zasniva na pre svega razumevanju trenutnog konteksta i formiranju koncepta utemeljenog na održivoj strategiji i spremnog da se u bilo kom trenutku prilagodi uslovima haotične urbane sredine. $\mathrm{U}$ svom prologu Hybrid Buildings za knjigu This is Hybrid, Stiven Hol na najbolji način suštinski definiše hibridnu arhitekturu i njen odnos sa kontekstom -

„Turbulentan kontekst koji definiše sadašnji trenutak zahteva neviđene arhitektonske i urbanističke prototipe sa društvenom kombinacijom koja će integrisati nove modele javnih prostora, zelene površine, programske jukstapozicije, nove prostorne organizacije $i$ interakcije, sve $u$ cilju preusmeravanja rapidnog procesa urbanizacije. Trenutno smo u vremenu novih mogućnosti, mogućnosti kombinovanja tehnološki najnaprednijih sistema, strategija zelenog urbanizma, slojevitog kulturnog programa unutar novog hibrida, dinamičnog $i$ poroznog. Jedino pitanje jeste: odakle početi?" [4].

\section{LITERATURA}

[1] R. Radović, "Forma grada", Orion Art, 2005.

[2] A. Coupland, "Reclaiming The City”, E \& FN Spon, London, 1997.

[3] J. Fenton, "Pamphlet Architecture 11: Hybrid Buildings", Princeton Architectural Press, 1985.

[4] S. Holl, "Hybrid Buildings", Expanded Edition Prologue by Steven Holl, iz A. P. Fernandes, J. Mozas, J. Arpa, "This is Hybrid”, Graficas Irudi s.l, Vitoria Gasteiz, 2014.

\section{Kratka biografija:}

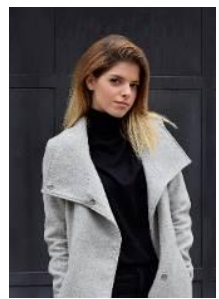

Sofia Rudan rođena je u Novom Sadu 1995. god. Master rad na Fakultetu tehničkih nauka iz oblasti Arhitektura i urbanizam - Arhitektonsko projektovanje odbranila je 2019.god.

kontakt: sofia.rudan@gmail.com 